Stereotactic

and Functional

Neurosurgery
Stereotact Funct Neurosurg 2015;93:310-315

DOI: $10.1159 / 000431373$
Received: December 16, 2014

Accepted after revision: May 15, 2015

Published online: July 29, 2015

\title{
Deep Brain Stimulation in Pathological Aggression
}

\author{
Marek Harat ${ }^{a}$ Marcin Rudaś ${ }^{b}$ Piotr Zieliński ${ }^{c} \quad$ Julita Birska $^{b}$ Pawel Sokal ${ }^{b}$ \\ ${ }^{a}$ Department of Public Health, Collegium Medicum, Nicolaus Copernicus University, Torun, ${ }^{b}$ Department of \\ Neurosurgery, 10th Military Hospital, Bydgoszcz, and ${ }^{C}$ Department of Sports Medicine, University of Physical \\ Education and Sport, Gdansk, Poland
}

\section{Key Words}

Aggression · Deep brain stimulation · Posteromedial

hypothalamus · Nucleus accumbens

\begin{abstract}
Background: We describe a case of deep brain stimulation in a patient with severe aggression refractory to conservative treatment. The targets of the stimulation were set bilaterally in the posteromedial hypothalamus and - in a second procedure due to its ineffectiveness - in the nucleus accumbens (NACC) bilaterally. Methods: In the first stage, we implanted electrodes into the posteromedial hypothalamus, after obtaining consent of the Bioethics Committee. In the early postoperative period, we observed significant improvement in the range of $50-90 \%$ in terms of quantity and quality of the attacks of aggression. After about 3 weeks, attacks of aggression started to return. Despite changes in the stimulation parameters there was no improvement. For this reason, based on the experience of surgery in patients with obsessive-compulsive disorder, Tourette syndrome and with morbid obesity, we decided to implant electrodes into the NAcc. Results: After 15 months of follow-up, the patient has no aggressive behavior, with no side effects. Conclusions: Although the stimulation of the posterior-medial hy-
\end{abstract}

pothalamus did not bring long-term benefits, its combination with bilateral stimulation of the NAcc practically freed the patient from aggressive disorders. It significantly improved the patient's quality of life.

(c) 2015 S. Karger AG, Basel

\section{Introduction}

Already in the 70s, Sano et al. [1, 2] reported good results of bilateral lesions in the posteromedial hypothalamus in patients with pathological aggression. In a paper published in 2005, Franzini et al. [3] describe the treatment of 2 patients using deep brain stimulation of the posteromedial hypothalamus. They achieved good control of aggressive behavior in these patients. Long-term results of posteromedial hypothalamic deep brain stimulation for patients with resistant aggressiveness were published in 2013 by Torres et al. [4].

The hypothalamus is a group of nuclei coordinating behavioral and autonomic disorders [4]. Its stimulation is considered a major hope for patients with erethism, but the world experience is scarce. On this basis, after approval by the local Bioethics Committee (the local ethical committee approved the treatment on February 10, 2012),

\section{KARGER 125}

(c) 2015 S. Karger AG, Base

$1011-6125 / 15 / 0935-0310 \$ 39.50 / 0$

E-Mail karger@karger.com

www.karger.com/sfn
Piotr Zieliński, MD, PhD

Department of Neurosurgery, 10th Military Hospital

Powstańców Warszawy 5 Street

PL-86-681 Bydgoszcz (Poland)

E-Mail pziel@awf.gda.pl 

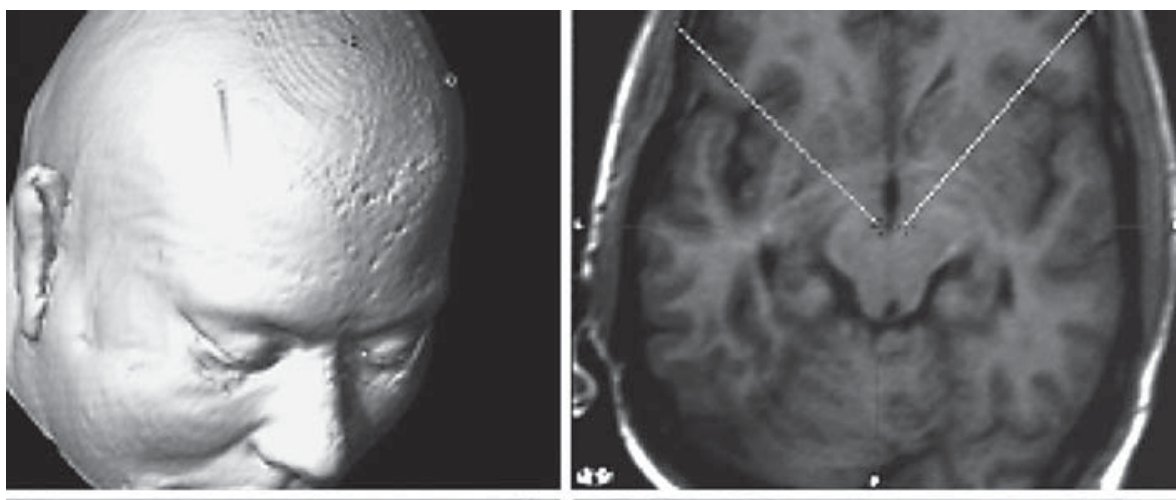

Fig. 1. Planning to set up the electrodes in the posteromedial hypothalamus.
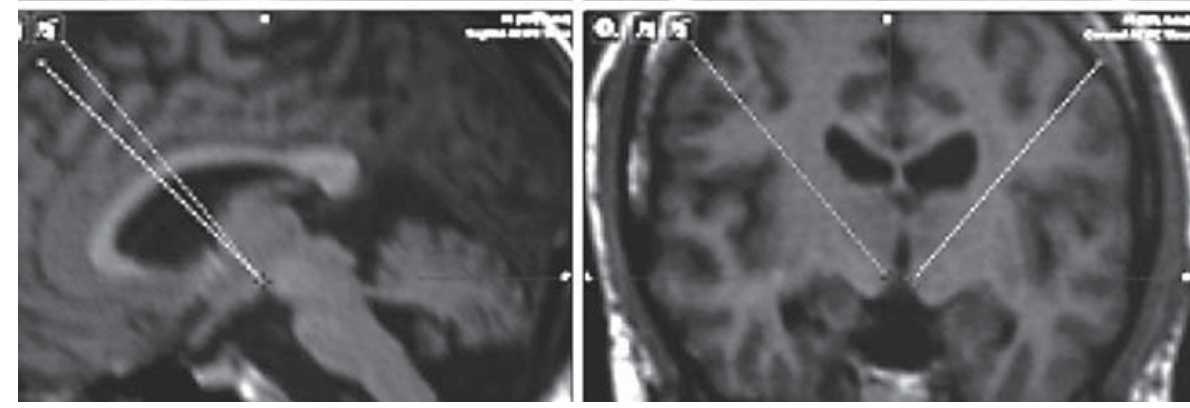

we qualified the patient with extremely severe aggression refractory to conservative treatment for deep brain stimulation.

\section{Case Description}

The 26-year-old woman was admitted to the Department of Neurosurgery because of attacks of aggression against herself and against the environment. In the interview, the patient was found to be born at the 25th week of gestation and diagnosed with cerebral palsy and obsessive-compulsive disorder (OCD). She was deaf-mute, with moderate mental retardation. She graduated from the special school for handicapped children at the high school; she attended therapy workshops. From the age of 16 her behavioral disorders, routing stereotyped and intrusive behaviour, touching, undressing, repeated checking and repeated entering the toilet, began to intensify. OCD was diagnosed. When the parents tried to correct her behavior, she hit herself on the head with her fists and bit her hands. She had sleep disorders (woke up at night and behaved as during the day), and she was overactive with self-injurious behavior and aggression to the environment.

The patient received various medications, but there was no improvement. Severity of aggression increased in the course of their administration, even in small doses. She was treated with chlorprothixen, clomipramine, clozapine, lithium, haloperidol, fluoxetine, sertraline, perazine, olanzapine, oxcarbazepine, risperidone, valproate, nitrazepam, clorazepam, carbamazepine, diazepam and clonazepam, but she felt best without drugs. She could not be left alone; practically all the time she spent with buckled belts or corset and had her hands immobilized.

Deep Brain Stimulation in Pathological Aggression
On the basis of the clinical picture she was qualified for surgery: the implantation of a stimulator for deep brain stimulation bilaterally to the posteromedial hypothalamus. Coordinates of the target in relation to the anterior-posterior commissure line from the midcommissural point were the following: on the left side lateral $5.03 \mathrm{~mm}$, anteroposterior $2.37 \mathrm{~mm}$ posterior and vertical $4.82 \mathrm{~mm}$ inferior; on the right side lateral $5.1 \mathrm{~mm}$, anteroposterior $4.52 \mathrm{~mm}$ posterior and vertical $5.26 \mathrm{~mm}$ inferior. The procedure was performed under general anesthesia; 4 contact electrodes for deep brain stimulation (ANS Cat 6149) were implanted on both sides (fig. 1). During the same procedure, the pulse generator was inserted in the subclavian pocket (Libra XP). Intraoperative control computed tomography (CT) showed the correct position of the electrodes (fig. 2).

The stimulator was originally started with the parameters of $180 \mathrm{~Hz}, 65 \mu \mathrm{s}, 1 \mathrm{~mA}$ and body polarity (+), contacts 1 (-). During the hospitalization we increased the strength of stimulation to 1.5 $\mathrm{mA}$. In the initial period of stimulation - up to 3 weeks of stimulation - the patient's condition improved significantly. The relationship with the family in the early postoperative period improved; after returning home, aggressive bouts decreased significantly by at least $50 \%$ - this applies to the frequency and severity of attacks. Also, improvement in reducing the length of time when the patient had to be under direct constraint was observed. However, from the 4 th week, she again began to grow violent and gradually returned to the state before the operation. For this reason, we modified the frequency of stimulation parameters to $20-30-50-70 \mathrm{~Hz}$ and set the pulse width at this time at $130-450 \mu$ s. There was no improvement in the patient's condition. Subsequently, we changed polarity to -1 , bipolar stimulation (-) 4 (+). At the amplitude above 1.1 $\mathrm{mA}$, she felt severe dizziness. 
Fig. 2. Control by intraoperative CT after insertion of electrodes into the hypothalamus.

Fig. 3. Planning the target in the NAcc.
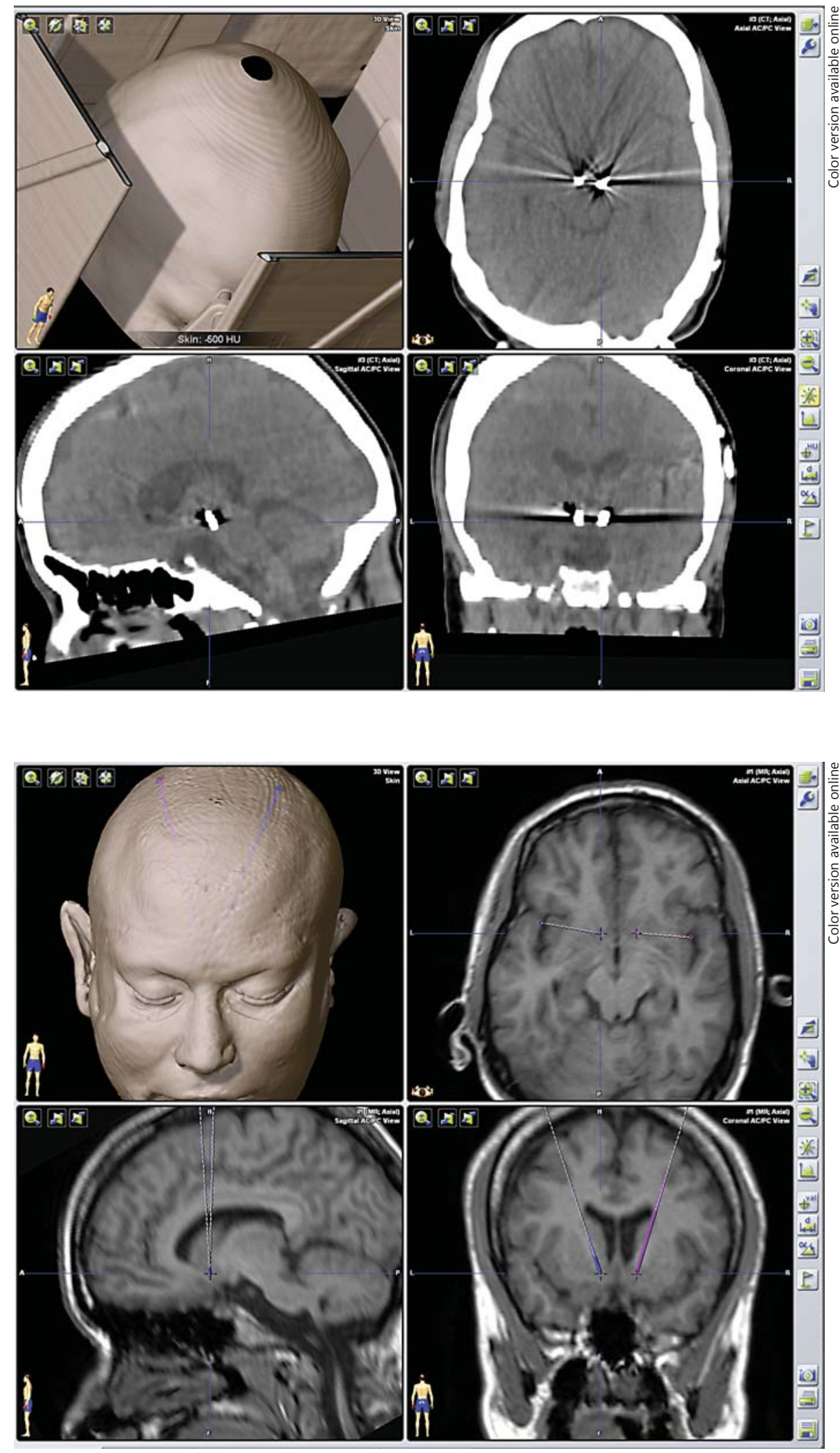
Fig. 4. Control by intraoperative CT after insertion of electrodes into the NAcc. The previously inserted electrodes are also visible in the hypothalamus.

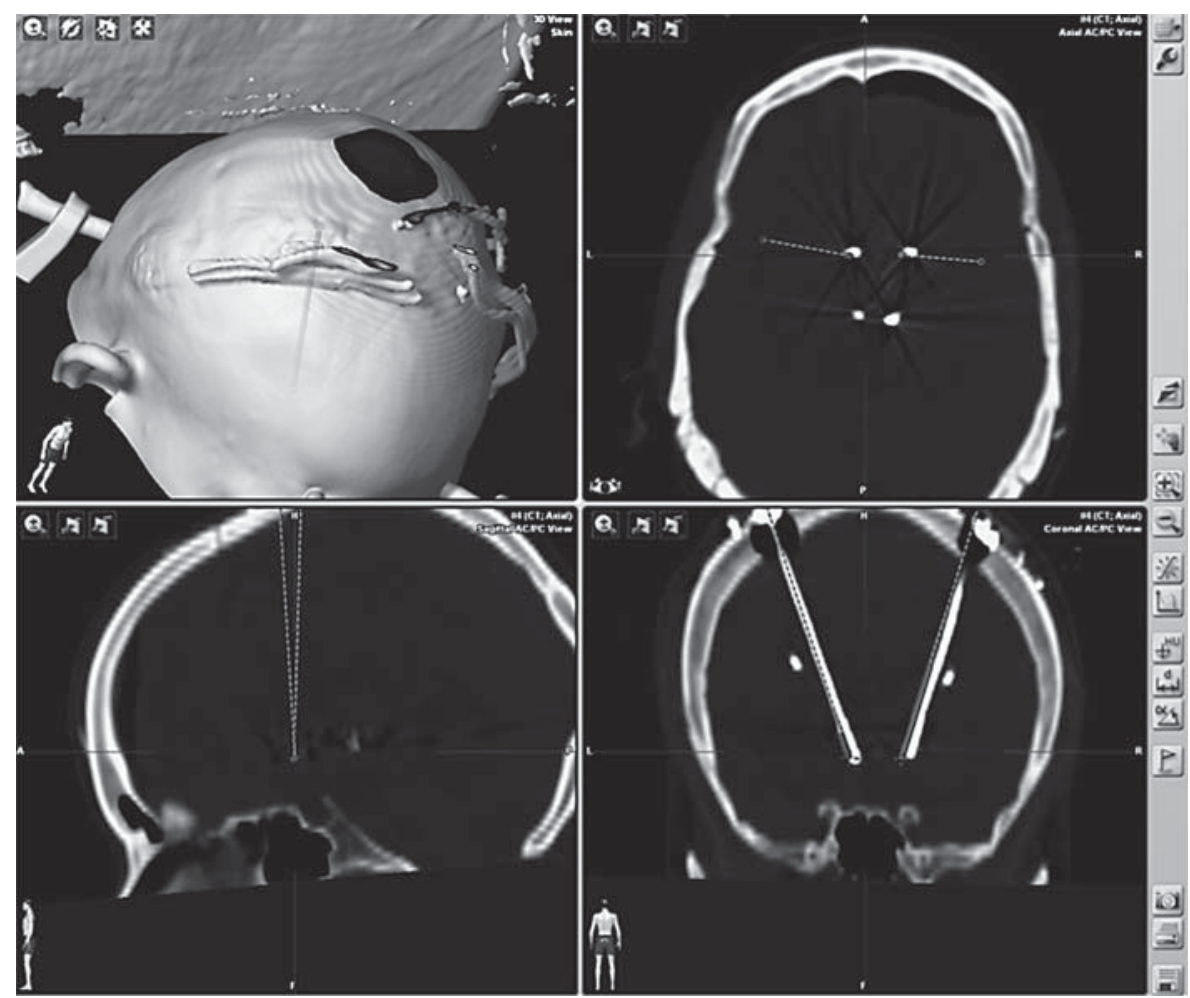

Finally, monopolar stimulation parameters were set to - body (+) $1(-)$ - in the range of amplitude $1.1 \mathrm{~mA}$, frequency $130 \mathrm{~Hz}$ and pulse width $247 \mu$ s. It was decided to implant a new pair of electrodes into the nucleus accumbens (NAcc). Electrodes were placed along the NAcc and anterior limb of the internal capsule (fig. 3). Coordinates of the target in relation to the anterior-posterior commissure line from the midcommissural point were the following: on the left side lateral $8.16 \mathrm{~mm}$, anteroposterior $17.05 \mathrm{~mm}$ anterior and vertical $6.95 \mathrm{~mm}$ inferior; on the right side lateral 8.95 $\mathrm{mm}$, anteroposterior $17.33 \mathrm{~mm}$ anterior and vertical $7.35 \mathrm{~mm}$ inferior.

Initial parameters of the NAcc stimulation were the following: frequency $=130 \mathrm{~Hz}$, pulse width $=208 \mu$ s, amplitude $=4.25 \mathrm{~mA}$, with 4 contacts active in monopolar mode. Concurrently hypothalamic stimulation was set to frequency $=130 \mathrm{~Hz}$, pulse width $=65$ $\mu$ s and amplitude $=1.25 \mathrm{~mA}$, with the first contact active in monopolar mode. After 4 months the amplitude in NAcc stimulation was elevated to $4.5 \mathrm{~mA}$ and decreased to $1.0 \mathrm{~mA}$ in the hypothalamic stimulation.

The decision was based on the experience of the treatment of OCD with this target and of Tourette syndrome, where we obtained an improvement of well-being, motivation, drive and normalization of hyperactive behaviors dependent upon external stimuli, as well as aggressive behavior.

The second treatment was also carried out under general anesthesia 5 months after the first operation. We obtained the consent of the local Bioethics Committee. The same type of electrodes and a pulse generator were used (ANS). Intraoperative CT showed the correct position of the electrodes (fig. 4). We activated the bipolar pacing stimulator using $1(-) 4(+), 130 \mathrm{~Hz}, 180 \mu$ s and initially 1.5
$\mathrm{mA}$. The patient tolerated stimulation well. Already during the hospitalization mild improvement was observed, and she improved during the first 6 months. Now, 15 months after surgery, the patient's condition improved significantly:

- attacks of aggression resolved completely;

- obsessions resolved (which contribute to acts of aggression);

- anxiety resolved.

During the day and night the patient does not require the use of coercive measures (which was previously necessary in order to avoid self-harming); she sleeps peacefully at night from about 21.30 to 9.30 (previously she slept only $2 \mathrm{~h}$ at night and functioned as during the day). She began to participate in family and social life - she travels with her family, is cycling and motorcycling, and takes part in family meetings. She does not require supervision any longer. Before surgery, she spent all the time with buckled belts; after the operation there is no need for this, and she stays in her room alone without parent supervision.

Fourteen months after the surgery, an accidental switching off of the stimulator occurred. She worsened a lot. She visited the neurosurgeon. After switching on the stimulator, her psychical status improved. It was a kind of inadvertent blinding of the follow-up.

\section{Discussion}

Deep brain stimulation may evoke or calm rage, fear and pain [4]. One of its targets is the hypothalamus.

The implantation of the first pair of electrodes, after an initial period of improvement, did ultimately not im- 


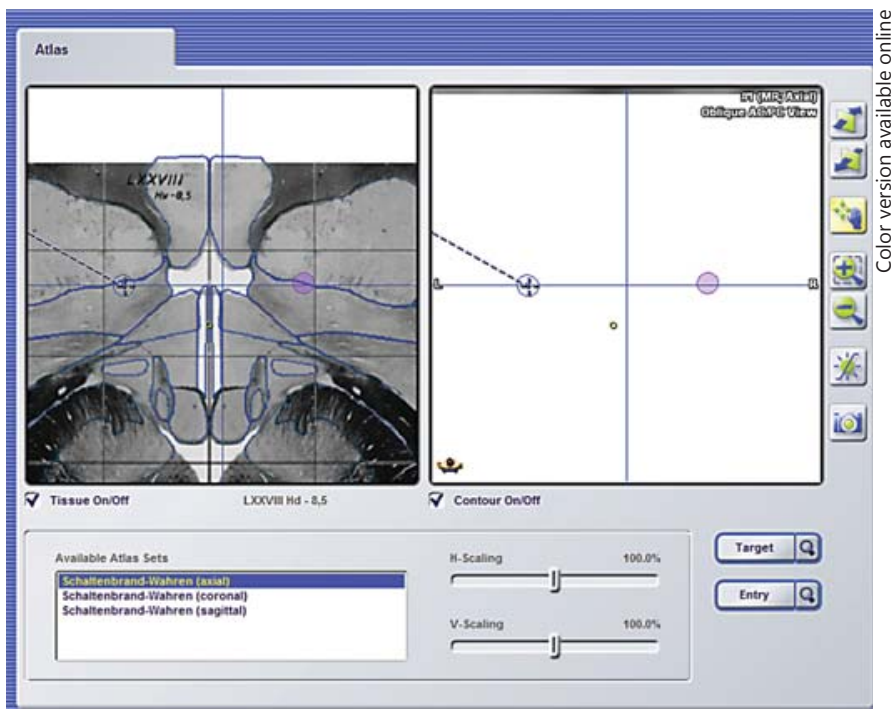

Fig. 5. Axial view of the Schaltenbrandt-Wahren atlas with planned targets for 2 electrodes.

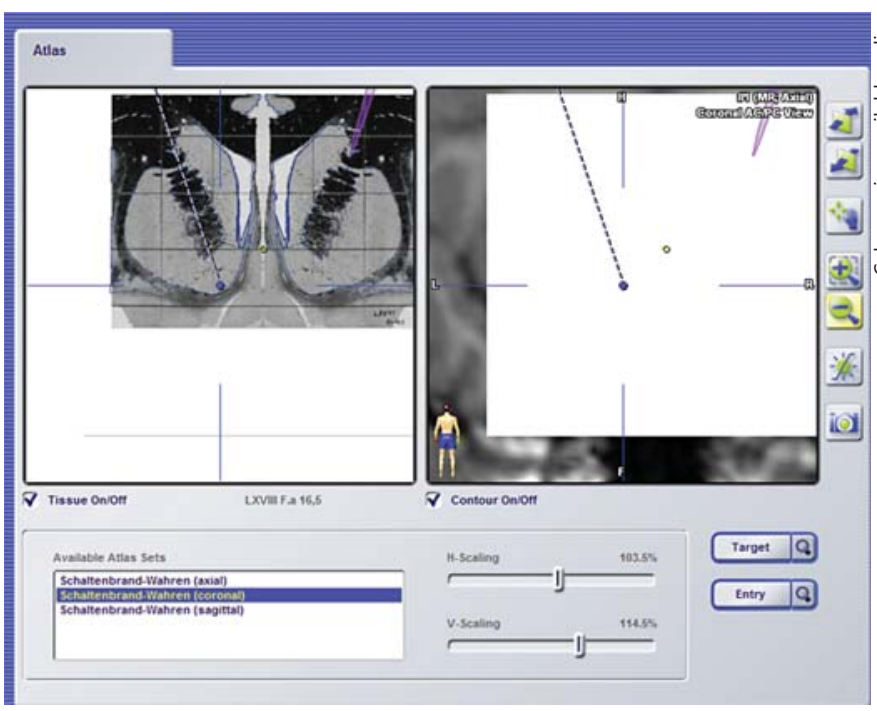

Fig. 7. Coronal view of the Schaltenbrandt-Wahren atlas with planned targets for an electrode.

prove the patient's condition. Hence, we searched for an alternative treatment of the very severe disease of our patient (fig. 5-7). Selecting the NAcc was dictated by our observations of the behavior of patients after insertion of electrodes in the case of OCD, Tourette syndrome or morbid obesity [5]. Often, these patients did notice aggressive behavior arising in the course of their disease or

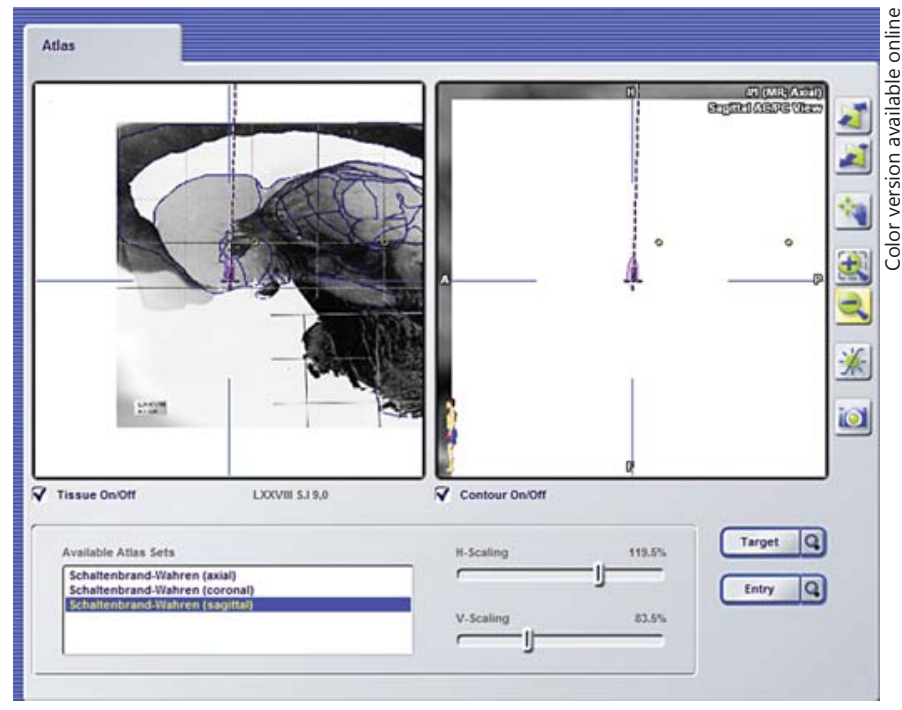

Fig. 6. Sagittal view of the Schaltenbrandt-Wahren atlas with planned targets for an electrode.

appearing as a specific attempt to compensate for the symptoms.

After stimulation of the NAcc, these disorders resolved, and the patient gradually improved. One may now discuss whether the good effect of the second operation is a success because of the implantation of electrodes into the NAcc only or if it results from the combination of stimulation in two areas of the brain. Of course, we could turn off the stimulator inserted into the posteriormedial hypothalamus, but considering the very good treatment effect, restoring the family hope and joy of life, we do not want to risk deterioration in our patient.

The second target was chosen due to the gradual worsening of the condition of the patient. The results were unexpectedly good, but it should be the aim of further research, examining for example the interconnections between the NAcc and posteromedial hypothalamus.

The published data on neurophysiology, animal models and human cases suggest a role of the NAcc in immediate reward circuits [6-14]. NAcc stimulation is proven to be effective for example in drug, nicotine and alcohol dependence [6-15]. We decided to treat the patient as dependent on food intake. This approach may also be supported by our own experience with the surgical treatment of OCD. The NAcc was chosen as a target because we have observed decreases in aggressive behavior in other cases treated with NAcc stimulation for other reasons (OCD, Tourette syndrome and pathological obesity). Our yet un- 
published case of a patient with OCD treated with bilateral NAcc stimulation proves the role of this structure in compulsive behavior, which may also be connected with craving for food. Modulation of NAcc activity resulted in a fast weight loss in the presented case without psychological deterioration. This may support the hypothesis of the important role of the limbic system in the pathogenesis of obesity after a hypothalamic lesion. The next case, operated on due to pathological aggression, was stimulated at the NAcc, but there are only moderately positive effects during the first weeks of follow-up. Maybe stimulation of the hypothalamus will be considered.

\section{Conclusions}

The placement of the second pair of electrodes significantly improved treatment outcome - now the patient is free from seizures of aggression. We do not observe any negative consequences of the stimulation. There is no need to keep strict supervision over the patient. She regained her drive and joy of life - she participates actively in family and social life.

\section{References}

1 Sano K, Mayanagi Y, Sekino H, Ogashiwa M, Ishijima B: Results of stimulation and destruction of the posterior hypothalamus in man. J Neurosurg 1970;33:689-707.

2 Sano K, Mayanagi Y: Posteromedial hypothalamotomy in the treatment of violent, aggressive behaviour. Acta Neurochir Suppl (Wien) 1988;44:145-151.

3 Franzini A, Marras C, Ferroli P, Bugiani O, Broggi G: Stimulation of the posterior hypothalamus for medically intractable impulsive and violent behavior. Stereotact Funct Neurosurg 2005;83:63-66.

4 Torres CV, Sola RG, Pastor J, Pedrosa M, Navas M, Garcia-Navarette E, Ezquiaga E, Garcia-Camba E: Long-term results of posteromedial hypothalamic deep brain stimulation for patients with resistant aggressiveness. J Neurosurg 2013;119:277-287.

5 Tomycz ND, Whiting DM, Oh MY: Deep brain stimulation for obesity - from theoretical foundations to designing the first human pilot study. Acta Neurochir (Wien) 2011;153: 2293-2306.

6 Benabid AL, Torres N: New targets for DBS. Parkinsonism Relat Disord 2012;18(suppl 1):S21-S23.
Halpern CH, Torres N, Hurtig HI, Wolf JA, Stephen J, Oh MY, Williams NN, Dichter MA, Jaggi JL, Caplan AL, Kampman KM, Wadden TA, Whiting DM, Baltuch GH: Expanding applications of deep brain stimulation: a potential therapeutic role in obesity and addiction management. Acta Neurochir (Wien) 2011;153:2293-2306.

-8 Mantione M, van de Brink W, Schuurman PR, Denys D: Smoking cessation and weight loss after chronic deep brain stimulation of the nucleus accumbens: therapeutic and research implications - case report. Neurosurgery 2010;66:E218.

-9 Halpern CH, Wolf JA, Bale TL, Stunkard AJ, Danish SF, Grossman M, Jaggi JL, Grady MS, Baltuch GH: Deep brain stimulation in the treatment of obesity. J Neurosurg 2008; 109 : 625-634.

10 Halpern CH, Torres N, Hurtig HI, Wolf JA, Stephen J, Oh MY, Williams NN, Dichter MA, Jaggi JL, Caplan AL, Kampman KM, Wadden TA, Whiting DM, Baltuch GH: Expanding applications of deep brain stimulation: a potential therapeutic role in obesity and addiction management. Acta Neurochir (Wien) 2011;153:2293-2306.
11 Sun B, Li D, Lin G, Zhan S, Zhang XX: Grading refractory anorexia nervosa for surgical treatment. Stereotact Funct Neurosurg 2012; 90(suppl 1):99.

-12 Taghva A, Corrigan JD, Rezai AR: Obesity and brain addiction circuitry: implications for deep brain stimulation. Neurosurgery 2012; 71:224-238.

13 Volkov ND, Wang GJ, Fowler JS, Telang F: Overlapping neuronal circuits in addiction and obesity: evidence of systems pathology. Philos Trans R Soc Lond B Biol Sci 2008;393: 3191-3200.

14 Stoeckel LE, Kim J, Weller RE, Cox JE, Cook EW 3rd, Horwitz B: Effective connectivity of a reward network in obese women. Brain Res Bull 2009;79:388-395.

15 Goncalves-Ferreira A, Simoes Do Cuto F, Rainha Campos A, Lucas Neto L, Salgado L, Lauterbach M, Goncalves-Ferreira D, Teixeira J, Rueff MC, Raposo H, Sequeira R: Deep brain stimulation for the treatment of refractory cocaine dependence. Stereotact Funct Neurosurg 2012;90(suppl 1):90. 